\title{
Molecular surveillance for drug resistance markers in Plasmodium vivax isolates from symptomatic and asymptomatic infections at the China-Myanmar border
}

Yan Zhao ${ }^{1+}$, Lin Wang ${ }^{1 \dagger}$, Myat Thu Soe ${ }^{2}$, Pyae Linn Aung ${ }^{2}$, Haichao Wei ${ }^{1}$, Ziling Liu' ${ }^{1}$, Tongyu Ma', Yuanyuan Huang ${ }^{1}$, Lynette J. Menezes ${ }^{3}$, Qinghui Wang ${ }^{1}$, Myat Phone Kyaw ${ }^{2}$, Myat Htut Nyunt ${ }^{4}$, Liwang Cui ${ }^{*}$ and Yaming $\mathrm{CaO}^{1 *}$ (1)

\begin{abstract}
Background: In the Greater Mekong sub-region, Plasmodium vivax has become the predominant species and imposes a major challenge for regional malaria elimination. This study aimed to investigate the variations in genes potentially related to drug resistance in P. vivax populations from the China-Myanmar border area. In addition, this study also wanted to determine whether divergence existed between parasite populations associated with asymptomatic and acute infections.

Methods: A total of 66 P. vivax isolates were obtained from patients with acute malaria who attended clinics at the Laiza area, Kachin State, Myanmar in 2015. In addition, 102 P. vivax isolates associated with asymptomatic infections were identified by screening of volunteers without signs or symptoms from surrounding villages. Slide-positive samples were verified with nested PCR detecting the 18S rRNA gene. Multiclonal infections were further excluded by genotyping at $m s p-3 a$ and $m s p-3 \beta$ genes. Parasite DNA from 60 symptomatic cases and 81 asymptomatic infections was used to amplify and sequence genes potentially associated with drug resistance, including pvmdr1, pvcrt-o, pvdhfr, pvdhps, and pvk12.

Results: The pvmdr1 Y976F and F1076 mutations were present in 3/113 (2.7\%) and 97/113 (85.5\%) P. vivax isolates, respectively. The K10 insertion in pvcrt-o gene was found in $28.2 \%$ of the parasites. Four mutations in the two antifolate resistance genes reached relatively high levels of prevalence: pvdhfr S58R (53.4\%), S117N/T (50.8\%), pvdhps A383G (75.0\%), and A553G (36.3\%). Haplotypes with wild-type pvmdr1 (976Y/997K/1076F) and quadruple mutations in pvdhfr (13l/57L/58R/61 M/99H/117T/173I) were significantly more prevalent in symptomatic than asymptomatic infections, whereas the pvmdr1 mutant haplotype 976Y/997K/1076 L was significantly more prevalent in asymptomatic than symptomatic infections. In addition, quadruple mutations at codons 57, 58, 61 and 117 of pvdhfr and
\end{abstract}

\footnotetext{
*Correspondence: liwangcui@usf.edu; ymcao@cmu.edu.cn

tYan Zhao and Lin Wang contributed equally to this work

1 Department of Immunology, College of Basic Medical Sciences, China

Medical University, Shenyang 110122, Liaoning, China

${ }^{3}$ Department of Internal Medicine, Morsani College of Medicine,

University of South Florida, 3720 Spectrum Boulevard, Suite 304, Tampa,

FL 33612, USA

Full list of author information is available at the end of the article
}

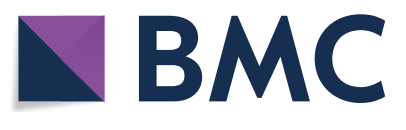

(c) The Author(s) 2020. This article is licensed under a Creative Commons Attribution 4.0 International License, which permits use, sharing, adaptation, distribution and reproduction in any medium or format, as long as you give appropriate credit to the original author(s) and the source, provide a link to the Creative Commons licence, and indicate if changes were made. The images or other third party material in this article are included in the article's Creative Commons licence, unless indicated otherwise in a credit line to the material. If material is not included in the article's Creative Commons licence and your intended use is not permitted by statutory regulation or exceeds the permitted use, you will need to obtain permission directly from the copyright holder. To view a copy of this licence, visit http://creativecommons.org/licenses/by/4.0/. The Creative Commons Public Domain Dedication waiver (http://creativecommons.org/publicdomain/zero/1.0/) applies to the data made available in this article, unless otherwise stated in a credit line to the data. 
double mutations at codons 383 and 553 of pvdhps were found both in asymptomatic and symptomatic infections with similar frequencies. No mutations were found in the pvk12 gene.

Conclusions: Mutations in pvdhfr and pvdhps were prevalent in both symptomatic and asymptomatic P. vivax infections, suggestive of resistance to antifolate drugs. Asymptomatic carriers may act as a silent reservoir sustaining drugresistant parasite transmission necessitating a rational strategy for malaria elimination in this region.

Keywords: Plasmodium vivax, Asymptomatic infection, Symptomatic infection, Drug resistance, Molecular markers, Northeast Myanmar

\section{Background}

Plasmodium vivax is the most geographically widespread Plasmodium species and also a cause of severe malaria [1-3]. Countries within the Greater Mekong Sub-region (GMS) have endorsed an ambitious plan to eliminate malaria by 2030 [4]. However, the proportion of malaria cases caused by $P$. vivax infection in Myanmar has increased steadily since 2012, especially in border areas [5]. Several features of $P$. vivax, including the formation of hypnozoites, the low density of infection, and the early production of gametocytes favor continuous transmission. Plasmodium vivax infections from asymptomatic carriers as a potential silent reservoir for transmission are common in both high- and low-endemic areas of Myanmar [6, 7]. Previous reports of asymptomatic Plasmodium falciparum infections carrying genes potentially associated with drug resistance suggest a possible spread of drug-resistant parasites in Myanmar [8, 9]. However, surveys of $P$. vivax drug resistance are scant because most drug resistance studies have focused on $P$. falciparum. Thus, monitoring the emergence and spread of $P$. vivax drug resistance, especially among asymptomatic carriers, is critical to achieve the goal of malaria elimination in the GMS.

Chloroquine $(\mathrm{CQ})$ and primaquine $(\mathrm{PQ})$ combination has been the frontline therapy for treating uncomplicated $P$. vivax cases. Plasmodium vivax resistance to CQ was first reported by Papua New Guinea in 1989 [10]. In the GMS, there have been sporadic reports of efficacy studies suggestive of emergence of CQ resistance (CQR) [11-13]. Two recent studies at the China-Myanmar border have demonstrated the declining efficacy of CQ against $P$. vivax and the potential emergence of drug resistance in this parasite [14, 15]. Although sulfadoxinepyrimethamine (SP) was rarely used to treat $P$. vivax, the substantial selective pressure exerted by the drug is thought to have continued during treatment of $P$. vivax and $P$. falciparum mixed-strain infections, resulting in the emergence of high-grade antifolate resistance in $P$. vivax populations [16]. Molecular surveillance studies indicated that $P$. vivax populations in southwestern Yunnan Province of China bordering Myanmar may be highly resistant to SP [17]. Because artemisinin-based combination therapy (ACT) is also used to treat mixedspecies infections $[18,19]$, $P$. vivax may have been under similar drug selective pressure as P. falciparum.

Currently, the molecular mechanisms underlying CQR remain unknown. It has been proposed that $P$. vivax $\mathrm{CQR}$ may involve similar molecular mechanisms as in P. falciparum. Multidrug resistance 1 gene ( $p v m d r 1)$ and putative transporter protein CG10 gene ( $p v c g 10$ or pvcrt-o), orthologous to $p f m d r 1$ and $p f c r t$ genes, respectively, have been suggested as possible genetic markers for CQR $[20,21]$. However, the first survey of the pvcrt-o gene in clinical isolates including treatment failure cases failed to identify an association between in vivo CQR with amino acid changes of pvcrt-o, suggesting the mechanism of CQR in $P$. vivax may be different from that in P. falciparum [22]. The K10 insertion in the first exon of pvcrt-o was the most common but also variable in different parasite populations [20,23,24], though it does not appear to correlate with CQR. Analysis of pvcrt-o mutant isoforms in yeast suggests that at least some pvcrt mutations may alter $P$. vivax sensitivity to CQ [25]. Whereas increased expression or copy number of $p v c r t-o$ was correlated with in vivo CQR in South America [26, 27], such a correlation was not identified in Papua Indonesia, where the level of CQR is high [28]. Recently, using a genetic cross and linkage mapping, upregulated pvcrt expression was identified as a mechanism of CQR [29]. In P. falciparum, polymorphisms in codons 86, 184, 1034, 1042 and 1246 of the pfmdrlgene were reported to be associated with CQR, which correspond to respective positions 91, 189, 1071, 1079 and 1291 in $p v m d r 1$ [21]. In pvmdr1, in vitro studies identified the $\mathrm{Y} 976 \mathrm{~F}$ mutation as a possible marker for CQR in P. vivax [20,30], whereas other studies did not identify such an association [31-34]. Similarly, whereas $p f m d r 1$ gene amplification was associated with resistance to mefloquine (MQ) in Thailand [30], increased expression of pvmdr1 and pvcrt-o was associated with CQR in Brazil [26]. Altogether, the roles of pvcrt-o and pvmdr1 in CQR in P. vivax are still not resolved [35]. Mutations in dihydrofolate reductase ( $p v d h f r$ ) and dihydropteroate synthase (pvdhps) have been associated with the altered clinical response to SP. F57L, S58R, T61M and S117N in $p v d h f r$ are linked to pyrimethamine resistance [19, 
36-39], while S382A/C, A383G, and A553G in pvdhps are responsible for sulfadoxine resistance [40]. Mutations in the propeller region of P. falciparum kelch 13 (pfk13) gene are the main genetic marker for artemisinin resistance [41]. It is logical to determine whether artemisinin drugs have imposed similar selective pressure on the pfk 13 ortholog on chromosome 12 of P. vivax (pvk12) [42-44].

Drug resistance affects the fitness and virulence of the malaria parasites [45]. This has been demonstrated in $P$. falciparum using in vitro growth competition $[46,47]$ and inferred from the reversion of resistance-mediating mutations to wild type (WT) in parasite populations after withdrawal of the drug [48]. Since less fit parasites are presumably to produce infections with lower parasitaemia, drug resistance may also affect the clinical presentations of the disease. Some mutations in pfcrt and $p f m d r 1$ were found to have higher prevalence in children with asymptomatic parasitaemia than those with parasitaemia and fever [49]. Similarly, in the GMS, pfmdr1 amplification was more prevalent in subclinical isolates than clinical isolates [50]. Under the same premise, mutations mediating $\mathrm{CQR}$ in $P$. vivax may have differential prevalence in asymptomatic and symptomatic infections.

To test this hypothesis and to obtain more comprehensive information of polymorphisms in candidate drug resistance genes in $P$. vivax in the China-Myanmar border area, $P$. vivax parasites from asymptomatic and acute infections were genotyped at the pvmdr1, pvcrt-o, pvdhfr, pvdhps and $p v k 12$ genes.

\section{Methods}

\section{Study sites and samples}

Samples were collected in 2015 in Laiza area of Waingmaw Township, Kachin State, Myanmar, located at the China-Myanmar border. This area has perennial transmission of $P$. vivax, which has become the predominant parasite species, and caused malaria outbreaks in recent years $[5,51]$. Passive case surveillance (PCS) was conducted at Laiza hospital and clinics serving the camps of internally displaced people (IDP), where malaria patients presenting with malaria-related signs and symptoms were diagnosed by microscopy and treated. Dried blood spots (DBS) on filter paper containing $200-300 \mu \mathrm{L}$ of peripheral blood were obtained by a standard finger-prick method, and thick and thin blood smears were prepared to identify parasite species and estimate parasitaemia.

Parasites were identified microscopically by two experienced microscopists. Three seasonal cross-sectional surveys (CSSs) were carried out in March, July and November in two IDP camps and surrounding villages through home visits that involved 5371, 4467 and 3997 participants without any signs or symptoms of malaria, respectively. DBS on filter paper were prepared and stored at $-20{ }^{\circ} \mathrm{C}$ for molecular analysis. At the time of the surveys, demographic information was obtained using a structured questionnaire. Parasite density was calculated by quantifying the number of parasites in 500 white blood cells (WBCs) on thick blood smears assuming $8000 \mathrm{WBCs} / \mu \mathrm{L}$ of blood [52]. This study was reviewed by institutional review boards of Pennsylvania State University and China Medical University. Written informed consent/assent was obtained from all malaria patients and participants.

\section{DNA extraction and molecular identification of $P$. vivax mono-infection}

Genomic DNA was extracted from DBS using the QIAamp DNA minikit (Qiagen, Hilden, Germany). Plasmodium vivax infection was confirmed by nested polymerase chain reaction (PCR) targeting the $18 \mathrm{~S}$ ribosomal RNA gene as described previously [53]. Then, the $P$. vivax parasites were genotyped using PCR and restriction fragment length polymorphism (PCR/ RFLP) at two polymorphic antigenic markers, merozoite surface protein-3 $\alpha(m s p-3 \alpha)[54,55]$ and $m s p-3 \beta$ [56]. Mixed and multiple infections were excluded, and only $P$. vivax monoclonal infections were used for genotyping drug resistance genes.

\section{PCR amplification for pvmdr1, pvcrt-o, pvdhfr, pvdhps and $p v k 12$ genes}

Fragments of pvmdr1 (expected amplicon sizes are 604 bp), pvcrt-o (327 bp), pvdhfr (755 bp), pvdhps (1259 bp) and pvk12 (1015 bp), which covered potential drug resistance associated mutations, were amplified by nested PCR using primers reported from previous studies [8, 42, 57, 58] (Additional file 1: Table S1). All reactions were carried out in a total volume of $30 \mu \mathrm{L}$ containing $19.4 \mu \mathrm{L}$ water, $0.6 \mu \mathrm{L}$ of each primer $(10 \mathrm{pM}), 1.8 \mu \mathrm{L}$ of $\mathrm{MgSO}_{4}(25 \mathrm{mM}), 0.6 \mu \mathrm{L}$ of KODPlus-Neo DNA polymerase $(5 \mathrm{U} / \mu \mathrm{L}), 3 \mu \mathrm{L}$ of $\mathrm{dNTP}$ mixture $(10 \mathrm{mM}$ each), and $3 \mu \mathrm{L}$ of $10 \times$ PCR buffer following the manufacturer's instructions (KOD 401, TOYOBO, Japan) with $1.0 \mu \mathrm{L}(5-10 \mathrm{ng})$ of genomic DNA. The primary and nested PCR conditions for the five genes were the same: initial denaturation at $98{ }^{\circ} \mathrm{C}$ for $2 \mathrm{~min} ; 35$ cycles of $98{ }^{\circ} \mathrm{C}$ for $15 \mathrm{~s}, 56^{\circ} \mathrm{C}$ for $30 \mathrm{~s}$, and $68^{\circ} \mathrm{C}$ for $1.5 \mathrm{~min}$; final extension of $68^{\circ} \mathrm{C}$ for $5 \mathrm{~min}$. The PCR products were resolved on a $1.2 \%$ agarose gel, and the sizes of the PCR products were determined using a 100-bp DNA ladder (3427A, TaKaRa, Japan). PCR products were stored at $-20^{\circ} \mathrm{C}$ until sequencing. 


\section{Sequence and statistical analyses}

The nested PCR products were purified and sent to SinoGenoMax (Beijing, China) for sequencing using an ABI 3730XL DNA Analyzer. For sequence accuracy, all DNA fragments were sequenced for both strands. Nucleotide and amino acid sequences of pvmdr1, pvcrt$o, p v d h f r, p v d h p s$ and $p v k 12$ were aligned using ClustalW implemented in MEGA7.0.26 with the following reference sequences from the Salvador I strain of $P$. vivax: pvmdr1 (PVX_080100), pvcrt-o (PVX_087980), pvdhfr (PVX_089950), pvdhps (PVX_123230) and pvk12 (PVX_083080). The single nucleotide polymorphism (SNP) frequency data were analysed using SPSS Statistics 22.0. Fisher's exact test, Mann-Whitney U test and Student's t test was used to determine statistical significance $(P<0.05)$. Principal component analysis $(\mathrm{PCA})$ was performed with ClustVis online program (https://biit. cs.ut.ee/clustvis/) on the parasites associated with clinical malaria and asymptomatic infections [59]. The gene sequences reported in this study were deposited in GenBank under accession numbers MT425613-MT425921.

\section{Results}

\section{Characteristics of study populations}

To compare $P$. vivax parasites present in asymptomatic and acute infections, CSSs and PCS were conducted in villages/IDP camps and malaria clinics, respectively. Microscopic examination of 13,835 blood smears in three seasonal CSSs identified, 102 asymptomatic $P$. vivax infections, which are defined as individuals with Plasmodium-positive blood smears but without any malaria-related symptoms at the time of examination and during the preceding week and the following week (Fig. 1). Nested PCR analysis excluded 15 negative samples and one $P$. vivax/P. falciparum mixed infection. Genotyping by PCR/RFLP of $m s p-3 \alpha$ and $m s p-3 \beta$ genes further excluded 5 multiclonal infections, leaving $81 P$. vivax isolates for genotyping drug resistance markers (Fig. 1). In addition, 66 clinical P. vivax infections diagnosed by microscopy were randomly selected from the 2015 PCS samples. After excluding 6 multiple infections, $60 P$. vivax monoclonal clinical isolates were used for genotyping drug resistance markers (Fig. 1). For the subjects with asymptomatic $P$. vivax infections, males and females were about equally present, and school age children were predominant (Table 1). For patients with patent $P$. vivax infections, males and females were also about equally present, but the age was significantly older than those in the asymptomatic group. For those with acute malaria, about half of them were febrile (axillary temperature $\geq 37.5^{\circ} \mathrm{C}$ ) at the time of presentation for care, and the majority of them (86.6\%) had 1 and 2 days of fever

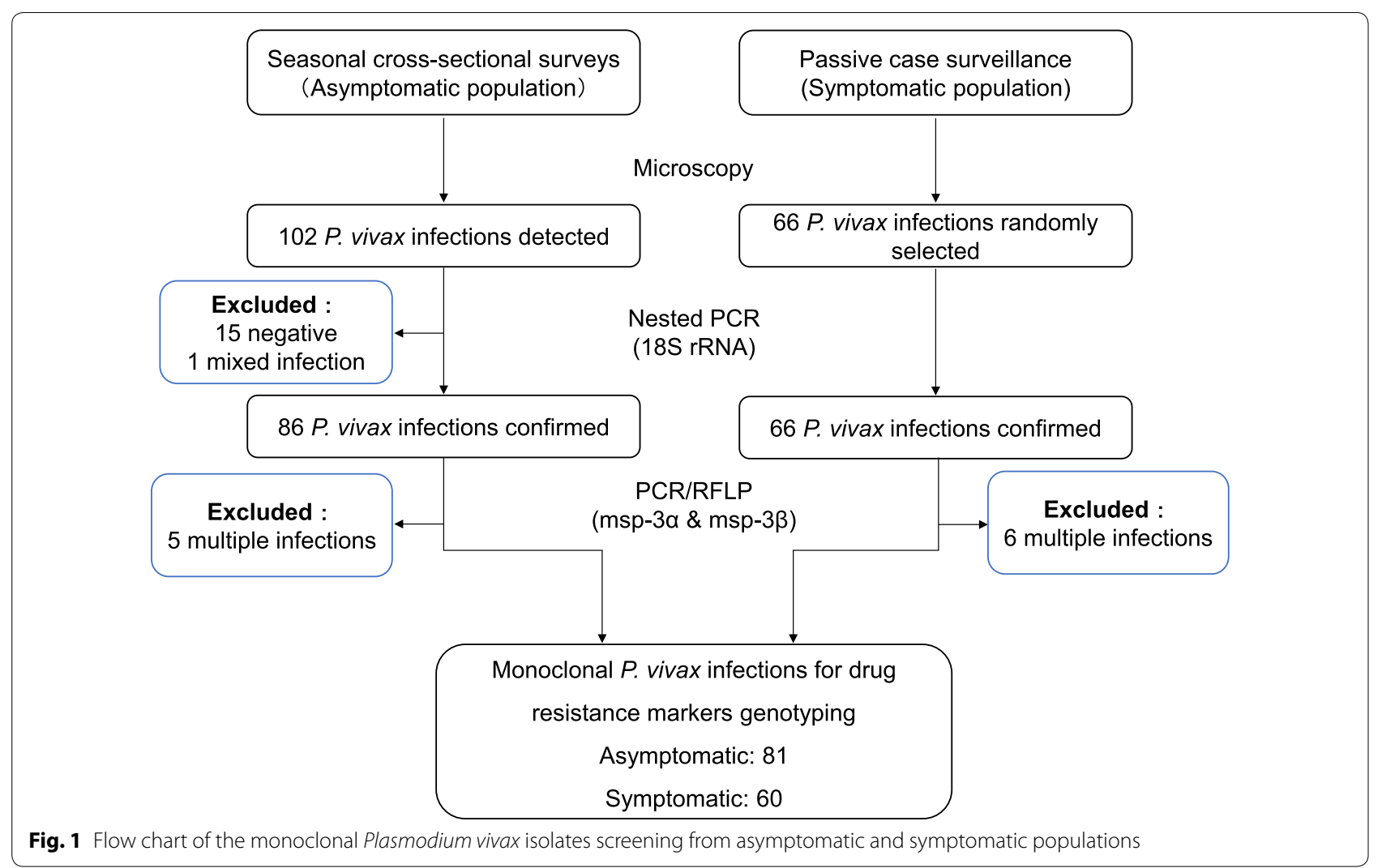


Table 1 Characteristics of asymptomatic and symptomatic $P$. vivax infections

\begin{tabular}{|c|c|c|}
\hline Characteristics & Asymptomatic & Symptomatic \\
\hline Number (\% male) & $81(53.1)$ & $60(48.3)$ \\
\hline Age [median (IQR) $]^{a}$ & $14(11-17)$ & $23(18-33)^{* * *}$ \\
\hline Fever on day $0[\mathrm{~N}(\%)]^{\mathrm{b}}$ & 0 & $31(51.7)$ \\
\hline \multicolumn{3}{|l|}{ Days with fever [N (\%)] } \\
\hline 1 & 0 & $26(43.3)$ \\
\hline 2 & 0 & $26(43.3)$ \\
\hline$\geq 3$ & 0 & $8(13.4)$ \\
\hline $\begin{array}{l}\text { Parasites density (parasites/ } \\
\mu \mathrm{L})[\text { mean (range) }]^{\mathrm{C}}\end{array}$ & $339(16-1648)$ & $1485(64-10,064)^{* * *}$ \\
\hline \multicolumn{3}{|l|}{$I Q R$ interquartile range } \\
\hline \multicolumn{3}{|l|}{ *** Indicates $P<0.001$} \\
\hline \multicolumn{3}{|c|}{ a Mann-Whitney U test } \\
\hline \multicolumn{3}{|c|}{${ }^{b}$ Fever is defined as axillary temperature $\geq 37.5^{\circ} \mathrm{C}$} \\
\hline
\end{tabular}

history. As expected, parasite density in symptomatic patients was significantly higher than that in asymptomatic infections $(P<0.001$, Student's t test).

Eighty-one asymptomatic and 60 symptomatic samples were used for PCR and sequencing analysis of pvmdr1, pvcrt-o, pvdhfr, pvdhps and pvk12 genes. The success rates were $57 / 81$ (70.4\%) pvmdr1, 52/81 (64.2\%) pvcrt$o, 61 / 81$ (75.3\%) pvdhfr, 41/81 (50.6\%) pvdhps and 55/81 (67.9\%) pvk12 for asymptomatic samples; and 56/60 (93.3\%) pvmdr1, 51/60 (85.0\%) pvcrt-o, 55/60 (91.7\%) pvdhfr, 39/60 (65.0\%) pvdhps and 55/60 (91.7\%) pvk12 for symptomatic samples.

\section{Pvmdr1 and pvcrt-o genes}

Mutations at codons 958, 976, 997 and 1076 in pvmdr1 were observed in P. vivax isolates. The T958M mutation was fixed in all parasite isolates and were not considered in analysis. The F1076 L was present in 97/113 (85.8\%) parasites, with 52/57 (91.2\%) and 45/56 (80.0\%) in asymptomatic and clinical infections, respectively. In contrast, Y976F was found only in 3/56 (5.5\%) of clinical isolates (Additional file 2: Table S2). Four pvmdr1 haplotypes were identified, including the WT and three mutants (976F, 997R and 1076L) (Table 2). The haplotype $976 \mathrm{Y} / 997 \mathrm{~K} / 1076 \mathrm{~L}$ was the most prevalent $(83.2 \%$ in total) in both asymptomatic and clinical isolates, with a significantly higher prevalence in asymptomatic than clinical infections $(91.2 \%$ vs $75.0 \%, P=0.021)$. In contrast, the prevalence of the WT was significantly lower in asymptomatic infections than that in clinical infections (1.8\% vs $16.1 \%, P=0.008)$ (Table 2 ).

More than 30\% isolates carried the K10 insertion in the pvcrt-o gene. Mutations at codons 2 and 3 (T2I and I3V) were detected in a few clinical isolates but were absent in asymptomatic isolates (Additional file 2: Table S2). WT was the most prevalent haplotype (68.0\%), followed by $\mathrm{K} 10$ insertion $(28.2 \%)$ among all the $P$. vivax isolates (Table 2).

\section{Pvdhfr and pvdhps genes}

For all isolates, mutations in $p v d h f r$ at codons 13,57 , $58,61,99$ and 117 were present in $2 / 116(1.7 \%), 42 / 116$ (36.2\%), 62/116 (53.4\%), 42/116 (36.2\%), 31/116 (26.7\%) and 59/116 (50.9\%) isolates, respectively. I13L and F57L were absent in the isolates from asymptomatic populations (Additional file 2: Table S2). The top three mutations in clinical isolates were S58R (54.5\%), T61M (38.2\%) and S117T (38.2\%), while in asymptomatic populations they were S58R (52.5\%), S117T (41.0\%) and T61M (34.4\%), F57I (34.4\%). Haplotype analysis of $p v d h f r$ for all isolates revealed nine distinct allelic forms (Table 2), including the WT haplotype, haplotypes carrying a single mutation (99S), double mutations (99S/117T and $58 \mathbf{R} / 117 \mathbf{N})$, triple mutations $(57 \mathbf{I} / 58 \mathbf{R} / 61 \mathbf{M})$, quadruple mutations $(57 \mathbf{L} / 58 \mathbf{R} / 61 \mathbf{M} / 117 \mathbf{T}$ and $57 \mathbf{I} / 58 \mathbf{R} / 61 \mathbf{M} / 117 \mathbf{T})$, and quintuple mutations $(13 \mathbf{L} / 57 \mathbf{I} / 58 \mathbf{R} / 61 \mathbf{M} / 117 \mathbf{T})$. A deletion type $(13 \mathrm{I} / 57 \mathrm{~F} / 58 \mathrm{~S} / 61 \mathrm{~T} / 99 \mathrm{H}-117 \mathrm{~S} / 173 \mathrm{I})$ was also identified. The prevalence of the quadruple mutant $57 \mathbf{L} / 58 \mathbf{R} / 61 \mathbf{M} / 117 \mathbf{T}$ differed significantly in frequency between the asymptomatic and clinical isolates $(0 \%$ vs $10.9 \%, P=0.004)$. Interestingly, the quadruple mutant $57 \mathbf{I} / 58 \mathbf{R} / 61 \mathbf{M} / 117 \mathbf{T}$ was only observed in isolates from asymptomatic populations (Table 2).

For pvdhps gene, eight mutations were identified, including S382A/C, A383G, K512M/E, A553G, E571Q and A647V. Most of the isolates carried A383G (75.0\%) and A553G (36.3\%), and they were prevalent in both parasite populations. The K512M and E571Q mutations were unique in $P$. vivax isolates from asymptomatic populations, whereas S382C, K512E and A647V only presented in clinical isolates (Additional file 2: Table S2). Haplotype analysis of pvdhps revealed eight distinct allelic forms (Table 2), including the WT haplotype, and haplotypes carrying a single mutation (383G), double mutations (383G/553G and 383G/571Q), triple mutations (382A/383G/553G, 383G/512M/553G and $383 \mathbf{G} / 553 \mathbf{G} / 647 \mathbf{V}$ ), and quadruple mutations (382C/383G/512E/553G). Overall, those harbouring a single mutation A383G were the most prevalent haplotype, present in 29/80 (36.3\%) of clinical isolates. WT at $13 / 41(31.7 \%)$ was the predominant haplotype in isolates from asymptomatic parasites, followed by the single mutant haplotype with $29.3 \%$ frequency (Table 2).

Three different tandem repeat variations were found in the $p v d h f r$ gene. Type 1 was identical to the Sal I reference sequence, type 2 had a H99S mutation, and 
Table 2 Prevalence of pvmdr1, pvcrt-o, pvdhfr and pvdhps haplotypes in asymptomatic and symptomatic infections

\begin{tabular}{|c|c|c|c|c|}
\hline \multirow[t]{2}{*}{ Genes (codons) } & \multirow[t]{2}{*}{ Haplotypes $^{\mathrm{a}}$} & \multicolumn{3}{|c|}{ \# of haplotypes/\# of sequenced isolates (\%) } \\
\hline & & Asymptomatic & Symptomatic & Total \\
\hline \multirow[t]{4}{*}{ pvmdr1 $(976 / 997 / 1076)^{b}$} & YKF & $1 / 57(1.8)$ & $9 / 56(16.1)^{* *}$ & 10/113 (8.8) \\
\hline & FKF & $0(0.0)$ & $3 / 56(5.4)$ & $3113(2.7)$ \\
\hline & YRF & $4 / 57(7.0)$ & $2 / 56(3.6)$ & $6 / 113(5.3)$ \\
\hline & YKL & $52 / 57(91.2)$ & $42 / 56(75.0)^{*}$ & $94 / 113(83.2)$ \\
\hline \multirow[t]{4}{*}{ pvcrt-o $\left(2 / 3 / \mathrm{K} 10\right.$ insertion $^{c}$} & $\mathrm{Tl}_{-}$ & $37 / 52(71.2)$ & $33 / 51(64.7)$ & $70 / 103(68.0)$ \\
\hline & TIK & $15 / 52(28.8)$ & $14 / 51(27.5)$ & $29 / 103(28.2)$ \\
\hline & $\mathrm{TV}_{-}$ & $0(0.0)$ & $1 / 51(2.0)$ & 1/103 (1.0) \\
\hline & $\mathrm{IIK}$ & $0(0.0)$ & $3 / 51(5.9)$ & $3 / 103(2.9)$ \\
\hline \multirow[t]{9}{*}{ pvdhfr (13/57/58/61/99/117/173) } & IFSTHSI & $1 / 61(1.6)$ & $0(0.0)$ & $1 / 116(0.9)$ \\
\hline & IFST-S| & $14 / 61(23.0)$ & $7 / 55(12.7)$ & $21 / 116(18.1)$ \\
\hline & IFSTSSI & 13/61 (21.3) & 17/55 (30.9) & $30 / 116(25.9)$ \\
\hline & IFSTST $\mid$ & $1 / 61(1.6)$ & 0/55 (0.0) & 1/116 (0.9) \\
\hline & $|F \mathbf{R T}-\mathbf{N}|$ & $11 / 61(18.0)$ & $9 / 55(16.4)$ & $20 / 116(17.2)$ \\
\hline & IIRMHSI & $4 / 61(6.6)$ & $0(0.0)$ & 4/116 (3.6) \\
\hline & |LRMHT| & $0(0.0)$ & $7 / 55(10.9)^{* * *}$ & $7 / 116(6.0)$ \\
\hline & |IRMHT| & $17 / 61(27.9)$ & 13/55 (23.6) & $30 / 116(25.8)$ \\
\hline & LIRMHTI & $0(0.0)$ & 2/55 (3.6) & 2/116 (1.7) \\
\hline \multirow[t]{8}{*}{ pvdhps (382/383/512/553/571/647) } & SAKAEA & $13 / 41(31.7)$ & 7/39 (17.9) & $20 / 80(25.0)$ \\
\hline & SGKAEA & $12 / 41(29.3)$ & $17 / 39(43.6)$ & $29 / 80(36.3)$ \\
\hline & SGKGEA & 8/41 (19.5) & $11 / 39(28.2)$ & $19 / 80(23.8)$ \\
\hline & SGKAQA & 2/41 (4.9) & $0(0.0)$ & $2 / 80(2.5)$ \\
\hline & AGKGEA & $3 / 41(7.3)$ & $2 / 39(5.1)$ & $5 / 80(6.3)$ \\
\hline & SGMGEA & $3 / 41(7.3)$ & $0(0.0)$ & $3 / 80(3.8)$ \\
\hline & SGKGEV & $0(0.0)$ & $1 / 39(2.6)$ & $1 / 80(1.3)$ \\
\hline & CGEGEA & $0(0.0)$ & $1 / 39(2.6)$ & $1 / 80(1.3)$ \\
\hline
\end{tabular}

The difference in the major haplotypes between asymptomatic and symptomatic infections was calculated by Fisher's exact test. ${ }^{*} \mathrm{P}<0.05,{ }^{* *} \mathrm{P}<0.01$, *** $\mathrm{P}<0.001$

a Mutant amino acids are shown in boldface

b For pvmdr1, the fixed T958M was not considered

c For pvcrt-o,_indicates no K10 insertion

Type 3 carried a deletion of six amino acids at positions 98-103 (THGGDN) (Fig. 2a). Type 1 accounted for comparable prevalence in asymptomatic $(34.0 \%)$ and symptomatic (40.0\%) infections, respectively. The prevalence of Type 3 in asymptomatic isolates was higher than that in symptomatic infections, and vice versa for Type 2, albeit without statistically significant difference (Fig. 2b). Of note, Type 3 carried the S117N mutation rather than S117T.

For pvdhps sequences, six different tandem repeat variations were identified with a variable number of tandem repeat unit G (E/D) (A/G/S) KLTN. Type 1, identical to the Sal I reference strain, was the most common in both asymptomatic (65.9\%) and clinical (82.1\%) infections. Other five types had different deletion or insertion of tandem repeat unit in different amino acids positions (Fig. 3a). Type 3 and Type 4 were found in both types of isolates. For other infrequent variants, Type 2 and Type 5 only presented in asymptomatic populations, while Type 6 was just observed in clinical isolates (Fig. 3b).

\section{Pvk12 gene}

Sequencing of $p v k 12$ gene from 110 parasite isolates did not detect any mutations (data not shown).

\section{PCA}

This study further examined whether parasites populations from the symptomatic and asymptomatic pools were divergent at these potential resistance markers. There were 23 isolates of each population, for which all five genes were successfully sequenced. PCA of $P$. vivax isolates using combined SNPs in pvmdr1, pvcrt-o, pvdhfr and pvdhps from all 46 samples (Additional file 3: Table S3) showed that parasite populations from asymptomatic and symptomatic parasite populations clustered together (Fig. 4), indicating similarity of the two 


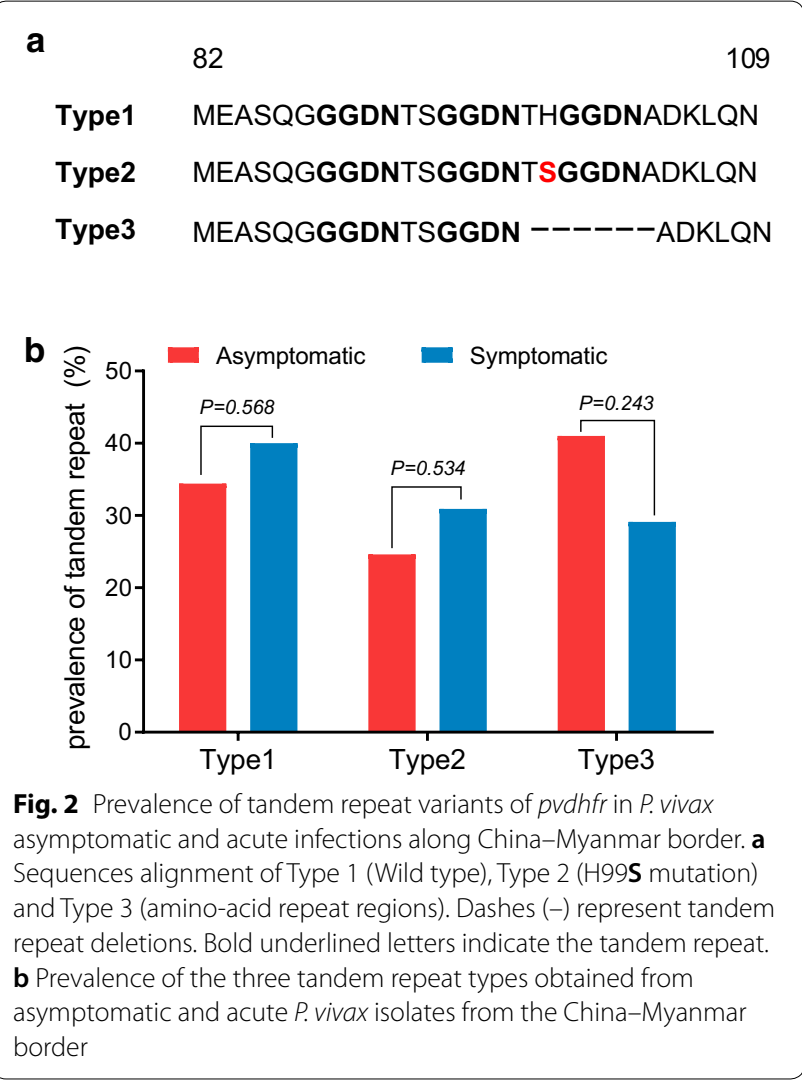

populations. Analysis of SNPs from each gene separately showed similar results (data not shown 3). It is noteworthy that only five haplotypes were identified from the 23 asymptomatic samples, indicating high prevalence of certain haplotypes.

\section{Discussion}

In Myanmar, CQR in P. vivax was reported as early as in the 1990s $[12,13]$. Drug resistance in P. falciparum and $P$. vivax isolates of asymptomatic malaria carriers has also been reported in high- and low-endemic regions of Myanmar [8, 9]. Recently, along the China-Myanmar border, the therapeutic responses of $P$. vivax malaria to CQ treatment were declining [14, 15]. Thus, this study compared the potential markers for CQR and antifolate resistance in asymptomatic and symptomatic $P$. vivax infections from this region.

The molecular mechanisms underlying CQR are not well understood, but mutations in pvmdr1 and expression of $p v c r t-o$ were implicated. For $p v m d r 1$, the Y976F mutation has been reported in $P$. vivax isolates from many malaria-endemic regions around the world [6064], and is associated with a decrease in in vitro sensitivity to CQ [20]. In this study, the Y976F mutation was relatively rare, with $5.5 \%$ detected only in samples from symptomatic infections. This prevalence was much lower than that found in Cambodia (89\%) [65] and Thailand (8-25\%) [62]. The T985M mutation is fixed in all parasite populations in Asia and it is not associated with CQR. Similarly, F1076L has not been found to be associated with CQR both in vivo and in vitro drug assays [66]. In this study, F1076L reached high prevalence of $85.8 \%$, which was concordant with previous reports from other Asian areas including India, Thailand and Myanmar [23, $60,61]$. The frequency of F1076L mutation in asymptomatic infections in Laiza township was twice as much as that in Shwegyin township of Myanmar [8]. The single mutation haplotype $976 \mathrm{Y} / 997 \mathrm{~K} / 1076 \mathrm{~L}$ was the most prevalent at the China-Myanmar border, similar to a previous report from India [60], but differed from a report from Yunnan, China, which showed WT as the dominant [67]. These geographical variations in $p v m d r 1$ gene may suggest different drug selection pressure imposed on $P$. vivax population in these Asian countries.

The role of pvcrt-o in CQR is controversial. Analysis of pvcrt-o isoforms in yeast suggest that a single amino acid substitution (S249P) slightly increased CQ transport [25], indicating a mild form of CQR. Other studies found that lysine $(\mathrm{K})$ insertion at position 10 of pvcrt-o gene may be associated with CQR $[20,23]$. This study observed a prevalence of $34 \%$ of K10 insertion in the pvcrt-o gene, higher than that found in India (9.4\%) and Thailand (0\%) [60-62], but lower than that detected in other regions of Myanmar (48.3-72.7\%) [23]. A recent study showed correlation of CQR with increased expression of pvcrt [29], which could not be evaluated with the DBS samples. Continuous monitoring of clinical efficacy of CQ and candidate molecular markers including pvcrt$o$ expression may be necessary to assess CQR in $P$. vivax populations in different parts of the GMS.

Results from this study suggest high-level resistance of the P. vivax parasites from the GMS to the antifolate drug SP. Resistance to antifolate drugs in $P$. falciparum and $P$. vivax was found to be associated with point mutations in dhps and dhfr [68]. For the pvdhfr gene, mutations at codons 50,58, 117 and 173 , corresponding to residues 51, 59, 108 and 164 in pfdhfr, confer resistance to pyrimethamine [69]. Double mutations (S58R and $\mathrm{S} 117 \mathrm{~N}$ ) were associated with a high level of resistance in $P$. vivax, whereas quadruple mutations (F57L/I, S58R, T61M and S117T) were more likely associated with SP treatment failure [38, 70]. Here, the prevalence of double or quadruple mutations (50.7\%) was much lower than that found along the Thailand border (100\%) and other areas of Myanmar (71\%-90\%) [23, $61]$, but much higher than what was found in southern China (9.2\%) [71]. Asymptomatic isolates in this study showed a much lower prevalence of both the double 
a

\begin{tabular}{|c|c|c|c|c|c|}
\hline Tyne1 & $\begin{array}{l}8 \\
8 \\
\text { GEAX GEGX }\end{array}$ & & $\begin{array}{l}\hat{\sigma} \\
\text { GEAX GEGX GDAX }\end{array}$ & & $\begin{array}{ll}\infty & \overline{1} \\
\bigoplus & \varnothing \\
\text { GDSX } & \text { GEAX }\end{array}$ \\
\hline Type2 & GEAX GEGX & & GEAX GEGX --ー- & GDSX & GDSX GEAX \\
\hline Type3 & GEAX GEGX & GEGX & GEAX GEGX GDAX & & GDSX GEAX \\
\hline Type4 & GEAX GEGX & GEGX & GEAX GEGX GDAX & GDSX & GDSX GEAX \\
\hline Type5 & GEAX GEGX GEAX & GEGX & GEAX GEGX GDAX & & GDSX GEA \\
\hline Type6 & GEAX GEGX & & --ー- ---- GDAX & & GDSX GEVX \\
\hline
\end{tabular}

b

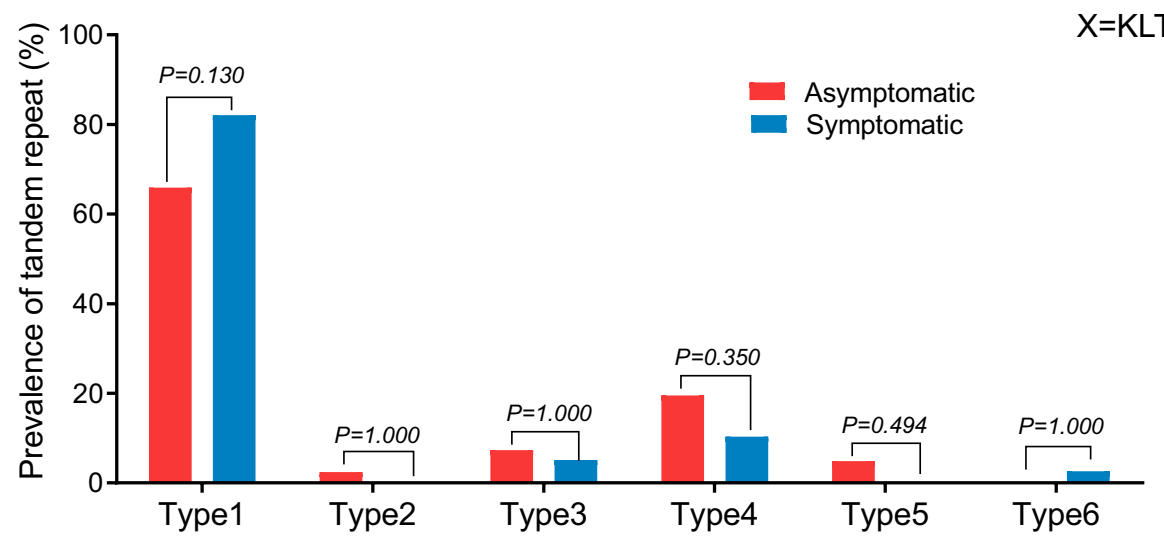

Fig. 3 Prevalence of tandem repeat variants of pvdhps in P. vivax asymptomatic and symptomatic infections along China-Myanmar border. a Sequences alignment of Type 1 (wild type) and Type 2-6 (amino-acid repeat regions). Insertions represent tandem repeat at amino acid position 616 and 638. Deletions at amino acid position 617 and 637. Bold letters indicate the tandem repeat. X is a representation of four amino acids (KLTN). b Prevalence of six tandem repeat types obtained from asymptomatic and acute infections from the China-Myanmar border area

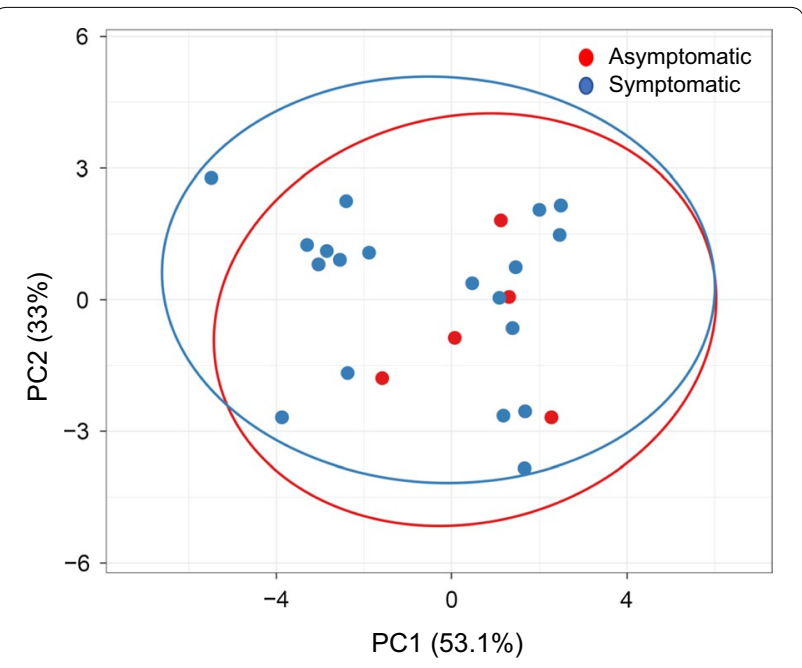

Fig. 4 Principal component analysis of $P$. vivax isolates obtained from asymptomatic and symptomatic populations with variables of four drug resistance-related genes (pvmdr1, pvcrt-o, pvdhfr and pvdhps). Twenty-three parasites from each group were used in the analysis. Since some parasites have identical haplotypes, their spots overlapped in the PCA plot. The two types of P. vivax population are circled and quadruple mutations than that found in southern Myanmar. Compared with the findings reported much earlier in Myanmar and Cambodia where double mutations (S58R and S117N) accounted for 91.7\% to $93.8 \%$ of the sequenced samples [36, 72], multiple mutations (more than 2) in the DHFR domain were more frequently in the present study. This may be a warning sign of the growing resistance of $P$. vivax to pyrimethamine over time in Southeast Asia.

Mutations at codons 382, 383, 512, 553 and 585 in pvdhps, corresponding to codons 436, 437, 540, 581 and 613 in pfdhps, may confer resistance to sulfadoxine. A recent study confirmed that A383G was associated with sulfadoxine resistance than other mutations when examined in transgenic rodent parasites expressing PvHPPKDHPS [73]. In addition, the double mutations A383G and A553G that possibly cause a disruption in the sulfadoxine-binding site in $P$. vivax were similar to those in $P$. falciparum [40]. At the China-Myanmar border, A383G reached $75 \%$. The prevalence of a haplotype with both the A383G and A553G mutations was 36.5\%, obviously lower than at the Thai-Myanmar and-Cambodian borders 
$(61.2 \%)$, and in other endemic areas of Myanmar (73.5\%) $[23,61]$.

For P. falciparum, triple mutations at codons 51,59 and 108 of pfdhfr and double mutations at codons 437 and 540 of pfdhps are associated with SP treatment failures [74]. The combination of $p v d h f r$ mutations at codons 57, 58, 61 and 117 and pvdhps mutations at codons 383 and 553 was identified in 13 (22\%) P. vivax isolates, of which 6 (46.2\%) were from asymptomatic carriers. These findings suggest that highly resistant $P$. vivax parasites to SP were present among asymptomatic and symptomatic infections at the China-Myanmar border.

Tandem repeats are a unique feature present in the $p v d h f r$ and $p v d h p s$, but it is not clear whether polymorphisms in these repeat regions contribute to resistance to SP. Tandem repeat region variations were observed in both asymptomatic and symptomatic infections. Consistent with previous studies, parasite isolates based on the $p v d h f r$ repeat region were typically separated into three types $[67,75]$. Type 1 tandem repeat variant was highly prevalent along with triple, quadruple or quintuple mutations, and about half of Type 3 variant co-existed with the double mutations $(58 \mathbf{R} / 117 \mathbf{N})$. This finding is consistent with that Type 1 and Type 3 are associated with increased resistance to SP [75-78]. It differed from the earlier findings in Cambodia where a large majority of isolates had two GGDN repeat units with double mutations $(58 \mathbf{R} / 117 \mathbf{N})$ [72], indicating that $P$. vivax with antifolate resistance evolved independently in different regions of the GMS. For pvdhps gene, five types of tandem repeat variants were identified for the first time in this study. Similar to $p v d h f r$, the majority of $p v d h p s$ tandem repeat types co-existed with mutations conferring SP resistance. However, further studies are essential to clarify the relationship between these polymorphisms and P. vivax sensitivity to SP.

PCA was used to explore if the parasite populations in symptomatic and asymptomatic infections could be differentiated based on the haplotypes of mutations in the five candidate resistance genes. While this method may have limitations to illustrate the genetic relatedness of different parasite isolates, the analysis nonetheless showed that the two clusters largely overlapped. While this supports the notion that asymptomatic infections are important reservoirs for sustaining continued transmission of the parasites, it also showed higher prevalence of certain haplotypes in asymptomatic parasite population. For single-gene haplotypes, the WT $p v m d r 1$ haplotype was significantly more prevalent in symptomatic patients than asymptomatic carriers, whereas the 976Y/997K/F1076L haplotype showed the opposite. In P. falciparum, some mutations in the drug transporter genes were found to confer fitness costs $[46,47]$. Although the effect of $p v m d r 1$ mutations on parasite's fitness is unknown, such differences in the prevalence of the WT and mutant alleles in asymptomatic and symptomatic infections, which had lower and higher parasitaemias, respectively, implies that the F1076L mutation may be associated with a fitness loss in the parasites. This mutation varies greatly in different parasite populations $[21,31,79,80]$, and its functional importance for CQR remains to be formally tested. It is also noteworthy that although this study screened more than 13,000 blood samples for asymptomatic infections, only a limited number of slide-positive samples were identified and used in the analysis, thus limiting the sample size and power of the analysis. There were also differences in age distribution between the two groups, which further complicates the comparison as host immunity is correlated with age and exposure. Therefore, although this study provided baseline information on candidate drug resistance genes in P. vivax in the China-Myanmar border region, the resistance mechanisms, except for antifolate resistance, demand future investigations.

\section{Conclusion}

All countries in the GMS have set an ultimate goal of eliminating malaria by 2030 . One of the main challenges is the resilience of $P$. vivax parasites to control measures, evidenced by the increased proportions of $P$. vivax parasites in many areas of the GMS. Molecular analysis of five potential drug resistance markers in P. vivax from the China-Myanmar border area showed prevalence of mutations in $p v m d r 1$, pvdhfr and pvdhps, suggesting resistance to antifolate drugs and possible $\mathrm{CQ}$. The higher prevalence of certain mutant alleles in asymptomatic infections also suggests fitness cost of the mutations, underscoring their potential involvement in drug resistance.

\section{Supplementary information}

Supplementary information accompanies this paper at https://doi. org/10.1186/s12936-020-03354-x.

Additional file 1: Table S1. PCR primer sequences for the amplification of sequences containing P. vivax pvmdr1, pvcrt-o, pvdhfr, pvdhps and pvk12 genes.

Additional file 2: Table S2. Prevalence of pvmdr1, pvcrt-o, pvdhfr and pvdhps amino acid substitutions in asymptomatic and symptomatic infections.

Additional file 3: Table S3. The variables used for each isolate input in the ClustVis online program. Column A indicaes the all variables of each gene. Second row indicates the samples used and Third raw indicates the groups. The reference and alternate allele is shown by 0 and 1 , respectively. 


\begin{abstract}
Abbreviations
ACT: Artemisinin-based combination therapy; CSS: Cross-sectional survey; CQ: Chloroquine; CQR: Chloroquine resistance; CRT: Chloroquine resistance transporter; DBS: Dried blood spot; DHFR: Dihydrofolate reductase; DHPS: Dihydropteroate synthase; GMS: Greater Mekong Sub-region; IDP: Internally displaced people; K12: Kelch-domain protein 12; MDR1: Multidrug resistance 1: MQ: Mefloquine; MSP: Merozoite surface protein; PCR: Polymerase chain reaction; PCR/RFLP: PCR and restriction fragment length polymorphism; PCS: Passive case surveillance; PQ: Primaquine; SP: Sulfadoxine-pyrimethamine: WBC: White blood cell; WT: Wild-type.
\end{abstract}

\section{Acknowledgements}

We appreciate all the participants for their willingness to take part in this study. We are indebted to the technicians, nurses and other workers from local hospitals for their assistance in completing the field surveys and sample collection.

\section{Authors' contributions}

YZ and LW performed the laboratory study and drafted the manuscript. LW, ZL, HW, TM and YH participated in the experimental work and data analysis. YZ, QW, MS and MK participated in field work. LM, MN, LC and YC conceived the study and revised the manuscript. All authors read and approved the final manuscript.

\section{Funding}

This study was supported by a grant from the National Institute of Allergy and Infectious Diseases, National Institutes of Health (U19AI089672).

\section{Availability of data and materials}

The datasets used and/or analysed during the current study are available from the corresponding authors upon request.

\section{Ethics approval and consent to participate}

The study protocol was approved by the institutional review boards of China Medical University, China, and Pennsylvania State University, USA. Informed consent was obtained from all adult participants or legal guardians of children.

\section{Consent for publication}

Not applicable.

\section{Competing interests}

The authors declare that they have no competing interests.

\section{Author details}

1 Department of Immunology, College of Basic Medical Sciences, China Medical University, Shenyang 110122, Liaoning, China. ${ }^{2}$ Myanmar Health Network Organization, Yangon, Myanmar. ${ }^{3}$ Department of Internal Medicine, Morsani College of Medicine, University of South Florida, 3720 Spectrum Boulevard, Suite 304, Tampa, FL 33612, USA. ${ }^{4}$ Department of Medical Research, Yangon, Myanmar.

Received: 7 May 2020 Accepted: 28 July 2020

Published online: 05 August 2020

\section{References}

1. Tjitra E, Anstey NM, Sugiarto P, Warikar N, Kenangalem E, Karyana M, et al. Multidrug-resistant Plasmodium vivax associated with severe and fatal malaria: a prospective study in Papua, Indonesia. PLoS Med. 2008;5:e128.

2. Medina-Morales DA, Montoya-Franco E, Sanchez-Aristizabal VD, Machado-Alba JE, Rodriguez-Morales AJ. Severe and benign Plasmodium vivax malaria in Embera (Amerindian) children and adolescents from an endemic municipality in Western Colombia. J Infect Public Health. 2016:9:172-80

3. Mukhtar MM, Eisawi OA, Amanfo SA, Elamin EM, Imam ZS, Osman FM, et al. Plasmodium vivax cerebral malaria in an adult patient in Sudan. Malar J. 2019:18:316.
4. WHO. Strategy for Malaria Elimination in the Greater Mekong Subregion (2015-2030). Geneva: World Health Organization; 2015.

5. Geng J, Malla P, Zhang J, Xu S, Li C, Zhao Y, et al. Increasing trends of malaria in a border area of the Greater Mekong Subregion. Malar J. 2019;18:309.

6. Zhao Y, Zeng J, Zhao Y, Liu Q, He Y, Zhang J, et al. Risk factors for asymptomatic malaria infections from seasonal cross-sectional surveys along the China-Myanmar border. Malar J. 2018;17:247.

7. Liu Z, Soe TN, Zhao Y, Than A, Cho C, Aung PL, et al. Geographical heterogeneity in prevalence of subclinical malaria infections at sentinel endemic sites of Myanmar. Parasit Vectors. 2019;12:83.

8. Nyunt MH, Shein T, Zaw NN, Han SS, Muh F, Lee SK, et al. Molecular evidence of drug resistance in asymptomatic malaria infections, Myanmar, 2015. Emerg Infect Dis. 2017;23:517-20.

9. Zhao Y, Liu Z, Soe MT, Wang L, Soe TN, Wei H, et al. Genetic variations associated with drug resistance markers in asymptomatic Plasmodium falciparum infections in Myanmar. Genes. 2019;10:692.

10. Rieckmann KH, Davis DR, Hutton DC. Plasmodium vivax resistance to chloroquine? Lancet. 1989;2:1183-4.

11. Phan GT, de Vries PJ, Tran BQ, Le HQ, Nguyen NV, Nguyen TV, et al. Artemisinin or chloroquine for blood stage Plasmodium vivax malaria in Vietnam. Trop Med Int Health. 2002;7:858-64.

12. Myat Phone K, Myint O, Myint L, Thaw Z, Kyin Hla A, Nwe Nwe Y. Emergence of chloroquine-resistant Plasmodium vivax in Myanmar (Burma). Trans R Soc Trop Med Hyg. 1993;87:687.

13. Guthmann JP, Pittet A, Lesage A, Imwong M, Lindegardh N, Min Lwin $M$, et al. Plasmodium vivax resistance to chloroquine in Dawei, southern Myanmar. Trop Med Int Health. 2008;13:91-8.

14. Yuan L, Wang Y, Parker DM, Gupta B, Yang Z, Liu H, et al. Therapeutic responses of Plasmodium vivax malaria to chloroquine and primaquine treatment in northeastern Myanmar. Antimicrob Agents Chemother. 2015;59:1230-5.

15. Xu S, Zeng W, Ngassa Mbenda HG, Liu H, Chen X, Xiang Z, et al. Efficacy of directly-observed chloroquine-primaquine treatment for uncomplicated acute Plasmodium vivax malaria in northeast Myanmar: a prospective open-label efficacy trial. Travel Med Infect Dis. 2019. https://doi. org/10.1016/j.tmaid.2019.101499.

16. Pukrittayakamee S, Chantra A, Simpson JA, Vanijanonta S, Clemens R, Looareesuwan S, et al. Therapeutic responses to different antimalarial drugs in vivax malaria. Antimicrob Agents Chemother. 2000;44:1680-5.

17. Huang B, Huang S, Su XZ, Tong X, Yan J, Li H, et al. Molecular surveillance of pvdhfr, pvdhps, and pvmdr-1 mutations in Plasmodium vivax isolates from Yunnan and Anhui provinces of China. Malar J. 2014;13:346.

18. Gogtay N, Kannan S, Thatte UM, Olliaro PL, Sinclair D. Artemisinin-based combination therapy for treating uncomplicated Plasmodium vivax malaria. Cochrane Database Syst Rev. 2013;2013:CD008492.

19. Imwong M, Pukrittakayamee S, Looareesuwan S, Pasvol G, Poirreiz J, White NJ, et al. Association of genetic mutations in Plasmodium vivax dhfr with resistance to sulfadoxine-pyrimethamine: geographical and clinical correlates. Antimicrob Agents Chemother. 2001;45:3122-7.

20. Suwanarusk R, Russell B, Chavchich M, Chalfein F, Kenangalem E, Kosaisavee $\mathrm{V}$, et al. Chloroquine resistant Plasmodium vivax: in vitro characterisation and association with molecular polymorphisms. PLOS ONE. 2007;2:e1089.

21. Brega S, Meslin B, de Monbrison F, Severini C, Gradoni L, Udomsangpetch $\mathrm{R}$, et al. Identification of the Plasmodium vivax mdr-like gene (pvmdr 1 ) and analysis of single-nucleotide polymorphisms among isolates from different areas of endemicity. J Infect Dis. 2005;191:272-7.

22. Nomura T, Carlton JM, Baird JK, del Portillo HA, Fryauff DJ, Rathore D, et al. Evidence for different mechanisms of chloroquine resistance in 2 Plasmodium species that cause human malaria. J Infect Dis. 2001;183:1653-61.

23. Nyunt $\mathrm{MH}$, Han JH, Wang $\mathrm{B}$, Aye KM, Aye KH, Lee SK, et al. Clinical and molecular surveillance of drug resistant vivax malaria in Myanmar (2009-2016). Malar J. 2017:16:117.

24. Joy S, Mukhi B, Ghosh SK, Achur RN, Gowda DC, Surolia N. Drug resistance genes: pvcrt-o and pvmdr-1 polymorphism in patients from malaria endemic South Western Coastal Region of India. Malar J. 2018;17:40.

25. Hassett MR, Riegel BE, Callaghan PS, Roepe PD. Analysis of Plasmodium vivax chloroquine resistance transporter mutant isoforms. Biochemistry. 2017;56:5615-22. 
26. Melo GC, Monteiro WM, Siqueira AM, Silva SR, Magalhaes BM, Alencar $A C$, et al. Expression levels of pvcrt-o and pvmdr-1 are associated with chloroquine resistance and severe Plasmodium vivax malaria in patients of the Brazilian Amazon. PLoS ONE. 2014;9:e105922.

27. Silva SR, Almeida ACG, da Silva GAV, Ramasawmy R, Lopes SCP, Siqueira $\mathrm{AM}$, et al. Chloroquine resistance is associated to multi-copy pvcrt-o gene in Plasmodium vivax malaria in the Brazilian Amazon. Malar J. 2018:17:267.

28. Pava Z, Handayuni I, Wirjanata G, To S, Trianty L, Noviyanti R, et al. Expression of Plasmodium vivax crt-o is related to parasite stage but not ex vivo chloroquine susceptibility. Antimicrob Agents Chemother. 2016;60:361-7.

29. Sa JM, Kaslow SR, Moraes Barros RR, Brazeau NF, Parobek CM, Tao D, et al. Plasmodium vivax chloroquine resistance links to pvert transcription in a genetic cross. Nat Commun. 2019;10:4300.

30. Suwanarusk R, Chavchich M, Russell B, Jaidee A, Chalfein F, Barends M, et al. Amplification of pvmdr 1 associated with multidrug-resistant Plasmodium vivax. J Infect Dis. 2008;198:1558-64.

31. Barnadas C, Ratsimbasoa A, Tichit M, Bouchier C, Jahevitra M, Picot S, et al. Plasmodium vivax resistance to chloroquine in Madagascar: clinical efficacy and polymorphisms in pvmdr1 and pvcrt-o genes. Antimicrob Agents Chemother. 2008;52:4233-40.

32. Orjuela-Sanchez P, de Santana Filho FS, Machado-Lima A, Chehuan YF, Costa MR, Alecrim M, et al. Analysis of single-nucleotide polymorphisms in the crt-o and mdr1 genes of Plasmodium vivax among chloroquineresistant isolates from the Brazilian Amazon region. Antimicrob Agents Chemother. 2009;53:3561-4.

33. Kim YK, Kim C, Park I, Kim HY, Choi JY, Kim JM. Therapeutic efficacy of chloroquine in Plasmodium vivax and the pvmdr1 polymorphisms in the Republic of Korea under mass chemoprophylaxis. Am J Trop Med Hyg. 2011;84:532-4.

34. Chaorattanakawee S, Lon C, Chann S, Thay KH, Kong N, You Y, et al. Measuring ex vivo drug susceptibility in Plasmodium vivax isolates from Cambodia. Malar J. 2017;16:392.

35. Price RN, Auburn S, Marfurt J, Cheng Q. Phenotypic and genotypic characterisation of drug-resistant Plasmodium vivax. Trends Parasitol. 2012;28:522-9.

36. de Pecoulas PE, Tahar R, Ouatas T, Mazabraud A, Basco LK. Sequence variations in the Plasmodium vivax dihydrofolate reductase-thymidylate synthase gene and their relationship with pyrimethamine resistance. Mol Biochem Parasitol. 1998;92:265-73.

37. Imwong M, Pukrittayakamee S, Renia L, Letourneur F, Charlieu JP, Leartsakulpanich $\mathrm{U}$, et al. Novel point mutations in the dihydrofolate reductase gene of Plasmodium vivax: evidence for sequential selection by drug pressure. Antimicrob Agents Chemother. 2003;47:1514-21.

38. Tjitra E, Baker J, Suprianto S, Cheng Q, Anstey NM. Therapeutic efficacies of artesunate-sulfadoxine-pyrimethamine and chloroquine-sulfadoxinepyrimethamine in vivax malaria pilot studies: relationship to Plasmodium vivax dhfr mutations. Antimicrob Agents Chemother. 2002;46:3947-53.

39. Eldin de Pecoulas P, Basco LK, Tahar R, Ouatas T, Mazabraud A. Analysis of the Plasmodium vivax dihydrofolate reductase-thymidylate synthase gene sequence. Gene. 1998;211:177-85.

40. Korsinczky M, Fischer K, Chen N, Baker J, Rieckmann K, Cheng Q. Sulfadoxine resistance in Plasmodium vivax is associated with a specific amino acid in dihydropteroate synthase at the putative sulfadoxine-binding site. Antimicrob Agents Chemother. 2004;48:2214-22.

41. Ariey F, Witkowski B, Amaratunga C, Beghain J, Langlois AC, Khim N, et al. A molecular marker of artemisinin-resistant Plasmodium falciparum malaria. Nature. 2014;505:50-5.

42. Popovici J, Kao S, Eal L, Bin S, Kim S, Menard D. Reduced polymorphism in the Kelch propeller domain in Plasmodium vivax isolates from Cambodia. Antimicrob Agents Chemother. 2015;59:730-3.

43. Wang M, Siddiqui FA, Fan Q, Luo E, Cao Y, Cui L. Limited genetic diversity in the PvK12 Kelch protein in Plasmodium vivax isolates from Southeast Asia. Malar J. 2016;15:537.

44. Deng S, Ruan Y, Bai Y, Hu Y, Deng Z, He Y, et al. Genetic diversity of the Pvk12 gene in Plasmodium vivax from the China-Myanmar border area. Malar J. 2016;15:528.

45. Rosenthal PJ. The interplay between drug resistance and fitness in malaria parasites. Mol Microbiol. 2013:89:1025-38.

46. Ochong E, Tumwebaze PK, Byaruhanga O, Greenhouse B, Rosenthal PJ. Fitness consequences of Plasmodium falciparum pfmdr1 polymorphisms inferred from ex vivo culture of Ugandan parasites. Antimicrob Agents Chemother. 2013;57:4245-51.

47. Hayward R, Saliba KJ, Kirk K. pfmdr1 mutations associated with chloroquine resistance incur a fitness cost in Plasmodium falciparum. Mol Microbiol. 2005;55:1285-95.

48. Laufer MK, Thesing PC, Eddington ND, Masonga R, Dzinjalamala FK, Takala $\mathrm{SL}$, et al. Return of chloroquine antimalarial efficacy in Malawi. N Engl J Med. 2006;355:1959-66.

49. Tukwasibwe S, Mugenyi L, Mbogo GW, Nankoberanyi S, Maiteki-Sebuguzi C, Joloba ML, et al. Differential prevalence of transporter polymorphisms in symptomatic and asymptomatic falciparum malaria infections in Uganda. J Infect Dis. 2014;210:154-7.

50. Brown T, Smith LS, Oo EK, Shawng K, Lee TJ, Sullivan D, et al. Molecular surveillance for drug-resistant Plasmodium falciparum in clinical and subclinical populations from three border regions of Burma/Myanmar: cross-sectional data and a systematic review of resistance studies. Malar J. 2012;11:333.

51. Zhou G, Lo E, Zhong D, Wang X, Wang Y, Malla S, et al. Impact of interventions on malaria in internally displaced persons along the China-Myanmar border: 2011-2014. Malar J. 2016;15:471.

52. Laman M, Moore BR, Benjamin J, Padapu N, Tarongka N, Siba P, et al. Comparison of an assumed versus measured leucocyte count in parasite density calculations in Papua New Guinean children with uncomplicated malaria. Malar J. 2014;13:145.

53. Snounou G, Viriyakosol S, Zhu XP, Jarra W, Pinheiro L, do Rosario VE, et al. High sensitivity of detection of human malaria parasites by the use of nested polymerase chain reaction. Mol Biochem Parasitol. 1993;61:315-20.

54. Bruce MC, Galinski MR, Barnwell JW, Snounou G, Day KP. Polymorphism at the merozoite surface protein-3alpha locus of Plasmodium vivax: global and local diversity. Am J Trop Med Hyg. 1999;61:518-25.

55. Cui L, Mascorro CN, Fan Q, Rzomp KA, Khuntirat B, Zhou G, et al. Genetic diversity and multiple infections of Plasmodium vivax malaria in Western Thailand. Am J Trop Med Hyg. 2003;68:613-9.

56. Yang Z, Miao J, Huang Y, Li X, Putaporntip C, Jongwutiwes S, et al. Genetic structures of geographically distinct Plasmodium vivax populations assessed by PCR/RFLP analysis of the merozoite surface protein 3beta gene. Acta Trop. 2006;100:205-12.

57. Lu F, Lim CS, Nam DH, Kim K, Lin K, Kim TS, et al. Genetic polymorphism in pvmdr1 and pvcrt-o genes in relation to in vitro drug susceptibility of Plasmodium vivax isolates from malaria-endemic countries. Acta Trop. 2011;117:69-75.

58. Ding S, Ye R, Zhang D, Sun X, Zhou H, McCutchan TF, et al. Anti-folate combination therapies and their effect on the development of drug resistance in Plasmodium vivax. Sci Rep. 2013;3:1008.

59. Metsalu T, Vilo J. ClustVis: a web tool for visualizing clustering of multivariate data using Principal Component Analysis and heatmap. Nucleic Acids Res. 2015;43:W566-70.

60. Anantabotla VM, Antony HA, Parija SC, Rajkumari N, Kini JR, Manipura R, et al. Polymorphisms in genes associated with drug resistance of Plasmodium vivax in India. Parasitol Int. 2019;70:92-7.

61. Tantiamornkul K, Pumpaibool T, Piriyapongsa J, Culleton R, Lek-Uthai U. The prevalence of molecular markers of drug resistance in Plasmodium vivax from the border regions of Thailand in 2008 and 2014. Int J Parasitol Drugs Drug Resist. 2018;8:229-37.

62. Rungsihirunrat K, Muhamad P, Chaijaroenkul W, Kuesap J, Na-Bangchang K. Plasmodium vivax drug resistance genes; Pvmdr1 and Pvcrt-o polymorphisms in relation to chloroquine sensitivity from a malaria endemic area of Thailand. Korean J Parasitol. 2015;53:43-9.

63. Imwong M, Pukrittayakamee S, Pongtavornpinyo W, Nakeesathit S, Nair S, Newton $P$, et al. Gene amplification of the multidrug resistance 1 gene of Plasmodium vivax isolates from Thailand, Laos, and Myanmar. Antimicrob Agents Chemother. 2008;52:2657-9.

64. Gonzalez-Ceron L, Montoya A, Corzo-Gomez JC, Cerritos R, Santillan F, Sandoval MA. Genetic diversity and natural selection of Plasmodium vivax multi-drug resistant gene (pvmdr1) in Mesoamerica. Malar J. 2017;16:261.

65. Lin JT, Patel JC, Kharabora O, Sattabongkot J, Muth S, Ubalee R, et al. Plasmodium vivax isolates from Cambodia and Thailand show high genetic complexity and distinct patterns of $P$. vivax multidrug resistance gene 1 (pvmdr1) polymorphisms. Am J Trop Med Hyg. 2013;88:1116-23. 
66. Shalini S, Chaudhuri S, Sutton PL, Mishra N, Srivastava N, David JK, et al. Chloroquine efficacy studies confirm drug susceptibility of Plasmodium vivax in Chennai, India. Malar J. 2014;13:129.

67. Lu F, Wang B, Cao J, Sattabongkot J, Zhou H, Zhu G, et al. Prevalence of drug resistance-associated gene mutations in Plasmodium vivax in Central China. Korean J Parasitol. 2012;50:379-84.

68. Hawkins VN, Joshi H, Rungsihirunrat K, Na-Bangchang K, Sibley CH. Antifolates can have a role in the treatment of Plasmodium vivax. Trends Parasitol. 2007:23:213-22.

69. Leartsakulpanich U, Imwong M, Pukrittayakamee S, White NJ, Snounou G, Sirawaraporn W, et al. Molecular characterization of dihydrofolate reductase in relation to antifolate resistance in Plasmodium vivax. Mol Biochem Parasitol. 2002;119:63-73.

70. Hastings MD, Maguire JD, Bangs MJ, Zimmerman PA, Reeder JC, Baird JK, et al. Novel Plasmodium vivax dhfr alleles from the Indonesian Archipelago and Papua New Guinea: association with pyrimethamine resistance determined by a Saccharomyces cerevisiae expression system. Antimicrob Agents Chemother. 2005;49:733-40.

71. Miao M, Yang Z, Cui L, Ahlum J, Huang Y, Cui L. Different allele prevalence in the dihydrofolate reductase and dihydropteroate synthase genes in Plasmodium vivax populations from China. Am J Trop Med Hyg. 2010;83:1206-11.

72. de Pecoulas PE, Tahar R, Yi P, Thai KH, Basco LK. Genetic variation of the dihydrofolate reductase gene in Plasmodium vivax in Snoul, northeastern Cambodia. Acta Trop. 2004;92:1-6.

73. Pornthanakasem W, Riangrungroj P, Chitnumsub P, Ittarat W, Kongkasuriyachai $D$, Uthaipibull C, et al. Role of Plasmodium vivax dihydropteroate synthase polymorphisms in sulfa drug resistance. Antimicrob Agents Chemother. 2016;60:4453-63.

74. Kublin JG, Dzinjalamala FK, Kamwendo DD, Malkin EM, Cortese JF, Martino LM, et al. Molecular markers for failure of sulfadoxine-pyrimethamine and chlorproguanil-dapsone treatment of Plasmodium falciparum malaria. J Infect Dis. 2002;185:380-8.

75. Lu F, Lim CS, Nam DH, Kim K, Lin K, Kim TS, et al. Mutations in the antifolate-resistance-associated genes dihydrofolate reductase and dihydropteroate synthase in Plasmodium vivax isolates from malaria-endemic countries. Am J Trop Med Hyg. 2010;83:474-9.

76. Rungsihirunrat K, Na-Bangchang K, Hawkins VN, Mungthin M, Sibley CH. Sensitivity to antifolates and genetic analysis of Plasmodium vivax isolates from Thailand. Am J Trop Med Hyg. 2007;76:1057-65.

77. Das S, Banik A, Hati AK, Roy S. Low prevalence of dihydro folate reductase (dhfr) and dihydropteroate synthase (dhps) quadruple and quintuple mutant alleles associated with SP resistance in Plasmodium vivax isolates of West Bengal, India. Malar J. 2016;15:395.

78. Alam MT, Bora H, Bharti PK, Saifi MA, Das MK, Dev V, et al. Similar trends of pyrimethamine resistance-associated mutations in Plasmodium vivax and P. falciparum. Antimicrob Agents Chemother. 2007;51:857-63.

79. Schousboe ML, Ranjitkar S, Rajakaruna RS, Amerasinghe PH, Morales $F$, Pearce $R_{\text {, }}$ et al. Multiple origins of mutations in the $\mathrm{mdr} 1$ gene-a putative marker of chloroquine resistance in P. vivax. PLoS Negl Trop Dis. 2015:9:e0004196.

80. Ngassa Mbenda HG, Wang M, Guo J, Siddiqui FA, Hu Y, Yang Z, et al. Evolution of the Plasmodium vivax multidrug resistance 1 gene in the Greater Mekong Subregion during malaria elimination. Parasit Vectors. 2020;13:67.

\section{Publisher's Note}

Springer Nature remains neutral with regard to jurisdictional claims in published maps and institutional affiliations.
Ready to submit your research? Choose BMC and benefit from:

- fast, convenient online submission

- thorough peer review by experienced researchers in your field

- rapid publication on acceptance

- support for research data, including large and complex data types

- gold Open Access which fosters wider collaboration and increased citations

- maximum visibility for your research: over $100 \mathrm{M}$ website views per year

At BMC, research is always in progress.

Learn more biomedcentral.com/submissions 